\title{
REVITALIZATION OF WAQF MANAGEMENT FOR SOCIAL ECONOMIC DEVELOPMENT OF EAST LUWU
}

\author{
REVITALISASI PENGELOLAAN WAKAF UNTUK \\ PEMBANGUNAN SOSIAL EKONOMI LUWU TIMUR
}

\author{
P-ISSN: 2085-5818 | E-ISSN: 2686-2107 \\ Url:https://uia.e-journal.id/alrisalah/1403 \\ DOI: 10.34005/alrisalah.v12i2.1403
}

\author{
Trisno Wardy Putra \\ UIN Alauddin Makassar \\ trisno.putra@uin-alauddin.ac.id
}

\author{
Devita Ayu Fildayanti \\ UIN Alauddin Makassar \\ devita29.akt@gmail.com
}

\begin{abstract}
Waqf is one of the sources of funds that has the potential to develop the people's economy. Even history proves that waqf that is maintained and developed productively is very helpful for the interests of the community. This study aims to determine the waqf management system in Tawakua Village, Angkona District, East Luwu Regency. The method used in this research is descriptive qualitative with a phenomenological approach. Data collection techniques through interview studies to 5 informants. The results of this study indicate that the management of waqf assets is managed directly by the village, and administration of the waqf pledge deed is carried out at KUA Angkona District. However, the role of waqf as a socio-economic development has not been optimal due to the lack of public knowledge and a lack of qualified human resources in the field of waqf. Therefore, it is necessary to revitalize the management of waqf so that the function of waqf as an instrument of economic development can be achieved.
\end{abstract}

Keywords: Waqf, Revitalization, Economic Development

\begin{abstract}
Abstrak: Wakaf menjadi salah satu sumber dana yang memiliki potensi dalam pengembangan ekonomi umat. Bahkan sejarah membuktikan bahwa wakaf yang dipelihara dan dikembangkan secara produktifsangat membantu kepentingan masyarakat.Penelitian ini bertujuan untuk mengetahui sistem pengelolaan wakaf di Desa Tawakua Kecamatan Angkona Kabupaten Luwu Timur. Metode yang digunakan dalam penelitian ini yaitu kualitatif deskriptif dengan pendekatan fenomenologi. Teknik pengambilan data melalui studi wawancara kepada 5 informan. Hasil penelitian ini menunjukkan bahwa pengelolaan harta benda wakaf dikelola secara langsung oleh desa, dan pengurusan administrasi akta ikrar wakaf dilakukan di KUA Kecamatan Angkona. Namun peran wakaf sebagai pembangunan sosial ekonomi belum optimal karena minimnya pengetahuan masyarakat dan kurangnya sumber daya manusia yang mumpuni di bidang wakaf. Oleh karena itu revitalisasi pengelolaan wakaf perlu dilakukan agar fungsi wakaf sebagai instrumen pembangunan ekonomi dapat tercapai.
\end{abstract}

Kata Kunci: Wakaf, Revitalisasi, Pembangunan Ekonomi

Trisno Wardy Putra \& Devita Ayu Fildayanti | Revitalization Of Waqf Management For Social Economic Development Of East Luwu 


\section{A. PENDAHULUAN}

Indonesia merupakan negara dengan jumlah populasi muslim terbanyak di dunia dengan jumlah penduduk muslim sebanyak 229,6 juta jiwa atau setara $87,2 \%$ dari total penduduk Indonesia dan $13 \%$ dari populasi muslim dunia. ${ }^{1}$ Religiusitas muslim di Indonesia juga cukup baik, terbukti dengan banyaknya umat Islam yang menunaikan ibadah haji di setiap tahunnya dan maraknya ibadah umrah. Jumlah muslim dan religiusitas masyarakat tersebut seharusnya memberikan korelasi dan efek positif terhadap persoalan wakaf di Indonesia. ${ }^{2}$

Wakaf merupakan salah satu sumber dana yang memiliki potensi dalam pengembangan ekonomi umat. ${ }^{3}$ Selain wakaf juga terdapat sumber dana sosial lain seperti zakat, infak, dan sedekah. Umat Islam di Indonesia telah lama mengenal dan menerapkan wakaf, yaitu sejak agama Islam masuk ke Indonesia. Wakaf sangat erat hubungannya dengan kegiatan sosial seperti halnya kegiatan sosial yang lain. Bahkan wakaf bisa dijadikan sebagai dana abadi umat yang memberikan manfaat dalam mensejahterakan masyarakat. ${ }^{4}$

Sejarah membuktikan bahwa wakaf yang dipelihara dan dikembangkan secara produktif sangat membantu kepentingan masyarakat. Namun kondisi saat ini memberikan gambaran bahwa perkembangan wakaf di Indonesia masih sangat jauh jika dibandingkan dengan negara-negara yang tergolong baik dalam mengelola dan mengembangkan wakafnya secara produktif seperti Arab Saudi, Bangladesh, Malaysia, Mesir, Amerika Serikat dan lainnya. ${ }^{5}$

Keberhasilan negara-negara Muslim adalah bukti bahwa wakaf mampu memberikan kontribusi dalam mengurai masalah perekonomian di sebuah negara. Mesir mampu membuktikan bahwa wakaf adalah salah satu sumber kesejahteraan masyarakat. Hal tersebut dikarenakan wakaf di Mesir dikelola dalam berbagai bidang seperti bidang properti, bidang

\footnotetext{
${ }^{1}$ A. Kholisdinuka, Jumlah Penduduk Muslim di Indonesia, Di Akses Pada Tanggal 30 Mei 2021 Pukul 09.14 WITA, https://news.detik.com.

${ }^{2}$ Nasrul Fahmi Zaki Fuadi, Wakaf sebagai Instrumen Ekonomi Pembangunan Islam, Economica: Jurnal Ekonomi Islam, Vol.9 No.1, 2018, h.151-177.

${ }^{3}$ Zainal Arifin Munir, Revitalisasi Manajemen Wakaf sebagai Penggerak Ekonomi Masyarakat, Journal de Jure, Vol.5 No.2, 2013,h.162-171.

${ }^{4}$ Fahmi Medias, Wakaf Produktif Dalam Perspektif Ekonomi Islam,La_Riba,Vol.4 No.1, 2010, h.7186.

${ }^{5}$ Nilna Fauza, Rekonstruksi Pengelolaan Wakaf: Belajar Pengelolaan Wakaf dari Bangladesh dan Malaysia, Universum, Vol.9 No.2, 2015, h.162-170.
}

Trisno Wardy Putra \& Devita Ayu Fildayanti | Revitalization Of Waqf Management For Social Economic Development Of East Luwu 
pertanian dan reklamasi tanah, dan bidang ekonomi. ${ }^{6}$ Bahkan Amerika Serikat juga memiliki aset wakaf yang produktif, yaitu sebuah proyek apartemen senilai US\$85 juta di atas tanah yang dimiliki oleh the Islamic Cultural Center of New York (ICCNY). Wakaf di Amerika Serikat dikelola oleh Kuwait Awqaf Public Foundation (KAPF), yaitu sebuah lembaga keuangan Islam profesional. Wakaf dikelola secara profesional, sehingga hasil yang diperoleh pun juga maksimal. ${ }^{7}$

Keberhasilan beberapa negara, baik negara muslim maupun sekuler sekalipun, membuktikan bahwa wakaf memiliki potensi yang sangat baik untuk dikembangkan. Manfaat yang dihasilkan pun sedikit banyak memberikan kontribusi dalam mewujudkan kemandirian ekonomi umat. Wakaf tentunya dapat diperhitungkan sebagai instrumen ekonomi Islam dalam sebuah negara.

Berdasarkan data Badan Wakaf Indonesia (BWI) bahwa selama ini wakaf di Indonesia baru dimanfaatkan untuk sektor sosial khususnya seperti pembangunan masjid, madrasah, dan tempat pemakaman. Kondisi ini terlihat sebagai potensi yang belum termanfaatkan dengan baik. Padahal sudah sejak lama umat islam di Indonesia mempraktikkan wakaf dalam kehidupan sehari-hari. ${ }^{8}$ Satu hal yang terkendala adalah ketika paradigma umumnya masyarakat tentang wakaf hanya sekedar wakaf keagamaan bukan wakaf pemberdayaan, sehingga harta wakaf hanya terkonsentrasi pada aset statis.

Seperti halnya Luwu Timur, yang merupakan salah satu daerah yang mayoritas penduduknya juga beragama islam. Berdasarkan data dari Badan Pusat Statistik tahun 2019, jumlah penduduk di Kabupaten Luwu Timur sebanyak 300.374 jiwa dengan jumlah penduduk muslim sebanyak $75,14 \%$ yaitu 229.653 jiwa. ${ }^{9}$ Namun mirisnya istilah wakaf sangat jarang sekali di dengar di kalangan masyarakat kalaupun ada itu hanya beberapa orang saja yang mengetahui. Wakaf yang sangat lazim mereka dengar adalah wakaf tanah. Kurangnya kesadaran masyarakat terkait wakaf, sumber daya manusia wakaf yang masih minim sehingga menimbulkan mispersepsi di kalangan masyarakat. Sebagaimana zakat yang masyarakat ketahui hanyalah zakat fitrah saja yang wajib dibayarkan, begitu pula

\footnotetext{
${ }^{6}$ Yuli YasinThayyeb, Pengelolaan Wakaf Produktif Di Mesir. Al-Awqaf: Jurnal Wakaf Dan Ekonomi Islam,Vol.7 No.2, 2012, h.1-12.

${ }^{7}$ Fahmi Medias, Wakaf Produktif Dalam Perspektif Ekonomi Islam,La_Riba,Vol.4 No.1, 2010, h.7186.

${ }^{8}$ Badan Wakaf Indonesia,Menelisik Manfaat Potensi Wakaf Uang Untuk Bantu Kaum Duafa, www.bwi.go.id di Akses Pada Tanggal 30 Mei 2021 Pukul 12.30 WITA.

${ }^{9}$ Badan Pusat Statistik, Jumlah Penduduk dan Penduduk Muslim di Kabupaten Luwu Timur, luwutimurkab.bps.go.id di Akses Pada Tanggal 30 Mei 2021 Pukul 09.55 WITA.
}

Trisno Wardy Putra \& Devita Ayu Fildayanti | Revitalization Of Waqf Management For Social Economic Development Of East Luwu 
dengan wakaf. Masyarakat tidak menyadari bahwa wakaf itu sangat penting dan menjadi salah satu instrumen pembangunan sosial ekonomi karena mereka beranggapan bahwa wakaf hanya di peruntukkan bagi orang-orang kaya saja.

Sehingga dari penjelasan di atas penulis berhipotesis bahwa pengelolaan wakaf di Kabupaten Luwu Timur perlu direvitalisasi. Melihat fenomena yang terjadi pada masyarakat di Kabupaten Luwu Timur mengenai wakaf yang telah dijelaskan di atas, mendorong penulis untuk memberikan tawaran solusi dengan memanfaatkan teknologi yang semakin berkembang hingga saat ini. Salah satunya dengan membuat website khusus untuk menangani masalah wakaf yang bekerja sama dengan pemerintah desa setempat. Website ini nantinya akan menyediakan berbagai fitur yang salah satu fungsinya yaitu untuk memberikan edukasi kepada masyarakat mengenai pentingnya wakaf bagi pemberdayaan ekonomi umat serta bagaimana pengelolaan wakaf yang baik. Tujuan dari website tersebut yaitu sebagai buku panduan atau pedoman bagi wakif dan nazhir dalam mengelola wakaf sebagaimana sesuai dengan ketentuan AlQuran dan hadis.

Dari hasil penelitian terdahulu bahwa salah satu yang menjadi faktor yang mempengaruhi tingkat kesadaran masyarakat dalam membayar zakat adalah ketersediaan informasi tentang zakat begitu pula wakaf. Hal ini berdasarkan pada penilitian oleh Herfita dan Haroni yang menyatakan bahwa faktor tersebut berada pada kategori baik. ${ }^{10}$ Selain itu, dari hasil penelitian yang dilakukan Syafiq bahwa upaya peningkatan kesadaran masyarakat dalam menunaikan Ziswaf dapat dilakukan dengan dua cara, yaitu yang pertama internal dengan meningkatkan religiusitas masyarakat, sehingga dengan semakin religius masyarakat diharapkan tingkat kesadarannya untuk menunaikan Ziswaf semakin tinggi. Kemudian dari sisi eksternal, yaitu dari sisi pengelolaan Ziswaf dibagi lagi menjadi dua yaitu sisi tata kelola Ziswaf yang baik dan akuntabel, dan dari sisi peran pemerintah dalam pengelolaan Ziswaf. ${ }^{11}$

Dari hasil penelitian terdahulu dan kajian sebelumnya, bahwa perlu adanya penelitian secara langsung kepada masyarakat Kabupaten Luwu Timur untuk mengetahui kondisi yang sebenarnya di lapangan. Hal ini

\footnotetext{
${ }^{10}$ Frida Nurul Hidayaty, Pengaruh Sosialisasi Perhitungan Praktis Zakat Mal Oleh Pengurus LAZ Terhadap Kesadaran Para Muzakki Untuk Berzakat Pada Zakat Center Thoriqhotul Jannah Cirebon, Institut Agama Islam Negeri Syekh Nurjati Cirebon, 2011, h. 10-18.

${ }^{11}$ Ahmad Syafiq, Peningkatan Kesadaran Masyarakat dalam Menunaikan Zakat, Infaq, Sedekah dan Wakaf (ZISWAF), Jurnal Zakat dan Wakaf, Vol.5 No.2, 2018, h.363-385.
}

Trisno Wardy Putra \& Devita Ayu Fildayanti | Revitalization Of Waqf Management For Social Economic Development Of East Luwu 
kemudian menjadi tolak ukur untuk mendalami lebih lanjut terkait pengelolaan tanah wakaf dan kondisi masyarakat disana.

\section{B. LANDASAN TEORI \\ Tinjauan Umum Wakaf}

Kata "wakaf" dalam bahasa Indonesia berasal dari kata Arab al-waqf, yang berarti menahan atau menghentikan. Kata lain yang sering digunakan sinonim dengan wakaf adalah al-hubus (jamaknya al-ahbas), yang berarti sesuatu yang ditahan atau dihentikan, maksudnya ditahan pokoknya dan dimanfaatkan hasilnya di jalan Allah. Kata "wakaf" dalam hukum Islam mempunyai dua arti. Arti kata kerja ialah tindakan mewakafkan, dan arti kata benda yaitu objek tindakan mewakafkan. Secara terminologis dalam hukum Islam, wakaf didefinisikan sebagai melembagakan suatu benda yang dapat diambil manfaatnya dengan menghentikan hak bertindak hukum pelaku wakaf atau lainnya terhadap benda tersebut dan menyalurkan hasilnya untuk kepentingan sosial dan kebaikan. ${ }^{12}$

Kata waqf (wakaf) dapat diartikan sebagai sesuatu yang subtansinya (wujud aktiva) dipertahankan, sementara hasil atau manfaatnya digunakan sesuai dengan keinginan waqif (orang yang mewakafkan hartanya). Wakaf merupakan amal Islami yang berwujud aktiva tetap, seperti tanah dan bangunan. Namun dalam perkembangannya terdapat implementasi wakaf dengan tunai sebagaimana yang dilakukan pada masa kekhalifahan Utsmaniyah (Haq, 2012). Menurut istilah meskipun terdapat perbedaan penafsiran, disepakati bahwa makna wakaf adalah menahan dzatnya benda dan memanfaatkan hasilnya atau menahan dzatnya dan menyedekahkan manfaatnya. ${ }^{13}$

Dasar hukum wakaf diambil dari AI-Quran dan As-sunah dan juga UU No. 41/2004 tentang wakaf pasal 4. Dalam UU No 41/2004 tentang wakaf pasal 4 bahwa tujuan wakaf itu sendiri adalah untuk memanfaatkan harta benda wakaf sesuai dengan fungsinya, Pasal 5 UU 41/2004 menyatakan bahwa fungsi wakaf adalah mewujudkan potensi dan manfaat ekonomis harta benda wakaf untuk kepentingan ibadah dan untuk

\footnotetext{
${ }^{12}$ Akhmad Sirojuddin Munir, Optimalisasi Pemberdayaan Wakaf Secara Produktif, Jurnal Ummul Qura,Vol.VI No.2, 2015, h.94-105.

${ }^{13}$ Ali Amin Isfandiar, Tinjauan Fiqh Muamalat dan Hukum Nasional tentang Wakaf di Indonesia,La_Riba: Jurnal Ekonomi Islam,Vol.II No.1, 2008,h.53-56.
}

Trisno Wardy Putra \& Devita Ayu Fildayanti | Revitalization Of Waqf Management For Social Economic Development Of East Luwu 
memajukan kesejahteraan umum. ${ }^{14}$ Dalil yang menjadi dasar disyariatkannya ibadah wakaf sebagai berikut. ${ }^{15}$

“Kamu sekali-kali tidak sampai kepada kebajikan (yang sempurna), sebelum kamu menafkahkan sehahagian harta yang kamu cintai dan apa saja yang kamu nafkahkan Maka Sesungguhnya Allah mengetahuinya." (Al-Imran: 92)

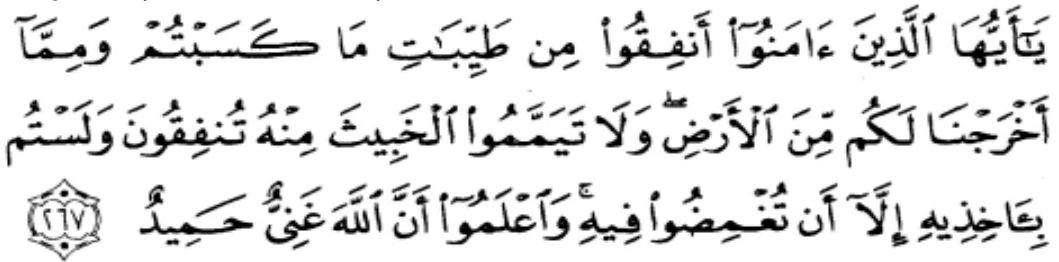

"Perumpamaan (nafkah yang dikeluarkan oleh) orang-orang yang menafkahkan hartanya di jalan Allah adalah serupa dengan sebutir benih yang menumbuhkan tujuh bulir, pada tiap-tiap bulir seratus biji. Allah melipat gandakan (ganjaran) bagi siapa yang Dia kehendaki. dan Allah Maha Luas (karunia-Nya) lagi Maha mengetahui." (AlBaqarah: 267)

\section{Rukun dan Syarat Wakaf}

Rukun merupakan suatu hal yang keberadaannya mutlak dipenuhi agar suatu perbutan hukum itu sah dan mempunyai akibat hukum. Adapun yang menjadi rukun dan syarat wakaf adalah sebagai berikut: ${ }^{16}$

1. Ada pihak yang berwakaf (wakif).

Orang yang melakukan perbuatan wakaf. Hendaklah wakif memiliki secara penuh hartanya, berakal dan dalam keadaan sehat rohaninya, tidak dalam keadaan terpaksa atau dalam keadaan jiwa yang tertekan, baligh, dan orang yang mampu bertindak secara hukum (rasyid).

2. Ada objek berupa harta kekayaan yang diwakafkan.

Harta benda yang akan diwakafkan harus jelas wujudnya atau zatnya dan bersifat abadi (barang berharga). Diketahui jumlah/ kadarnya, dimiliki penuh oleh orang yang berwakaf, hartanya berdiri sendiri, tidak bercampur atau melekat kepada harta lain.

3. Ada penerimaan dan pengelolaan harta wakaf (nadzir).

\footnotetext{
${ }^{14}$ Jubaedah, Dasar Hukum Wakaf,TAZKIYA: Jurnal Keislaman, Kemasyarakatan dan Kebudayaan,Vol.18 No.2, 2017, h.256-265.

${ }^{15}$ Choirun Nissa, Sejarah, Dasar Hukum dan Macam-macam Wakaf, TAZKIYA: Jurnal Keislaman, Kemasyarakatan dan Kebudayaan,Vol.18 No.2, 2017, h.214-217.

${ }^{16}$ Jubaedah, Dasar Hukum Wakaf, TAZKIYA: Jurnal Keislaman, Kemasyarakatan dan Kebudayaan,Vol.18 No.2, 2017, h.256-265.
}

Trisno Wardy Putra \& Devita Ayu Fildayanti | Revitalization Of Waqf Management For Social Economic Development Of East Luwu 
Sasaran yang berhak menerima hasil atau manfaat wakaf. Dapat dibagikan kepada wakaf khairy dan wakaf dzurry. Wakaf Khairy adalah wakaf dimana Al-Wakif tidak membatasi sasaran wakafnya untuk pihak tertentu, tetapi untuk kepentingan umum. Wakaf Dzurry adalah wakaf yang al-Wakif membatasi sasaran wakafnya untuk pihak tertentu, yaitu keluarga keturunannya.

4. Adanya sighat

Pernyataan pemberian wakaf, baik secara lafadz, tulisan maupun isyarat. Ucapan mengandung kata-kata yang menunjukan kekalnya amalan wakaf

tersebut (ta'bid), ucapan direalisasikan segera (tanjiz), ucapan bersifat pasti, ucapan tersebut tidak diikuti oleh syarat yang membatalkan amalanwakaf. ${ }^{17}$

\section{Konsep Wakaf Produktif}

Terdapat macam-macam wakaf yang dikategorikan berdasarkan bentuk manajemennya, keadaan wakif, ekonomi, bentuk hukumnya, tujuannya, dan jenis barangnya. Sedangkan untuk macam-macam wakaf berdasarkan sudut pandang ekonomi sendiri terbagi menjadi dua yaitu wakaf langsung dan wakaf produktif. ${ }^{18}$

1. Wakaf langsung adalah wakaf yang diberikan langsung kepada orang-orang yang berhak. Contoh dari wakaf langsung adalah wakaf masjid, sekolah, rumah sakit, makam, dan lain sebagainya. Wakaf langsung manfaatnya dapat langsung dirasakan oleh masyarakat dan aset wakafnya dapat dijadikan modal tetap yang selalu bertambah di tiap tahunnya.

2. Wakaf produktif adalah harta atau benda benda yang diwakafkan untuk dipergunakan dalam kegiatan produksi yang menghasilkan, kemudian hasilnya dimanfaatkan sesuai dengan tujuan wakaf. Contoh dari wakaf produktif adalah wakaf tanah yang digunakan untuk bercocok tanam, mata air untuk dijual airnya, jalan dan jembatan untuk dimanfaatkan sebagai jasa penyeberangan dan ongkosnya diambil dari orang yang menggunakannya. Wakaf produktif dikelola dengan profesional sehingga menghasilkan keuntungan dan keuntungannya dapat dimanfaatkan sesuai dengan tujuan wakaf.

Perbedaan antara wakaf langsung dan wakaf produktif adalah terletak pada manajemen pengelolaan dan cara pelestarian wakaf tersebut.

\footnotetext{
${ }^{17}$ Asep Dadan Suganda, Konsep Wakaf Tunai,Jurnal Ekonomi Islam, Vol.5 No.2, 2004, h.5-9.

${ }^{18}$ Qahaf, Mundzir,Manajemen Wakaf Produktif,(Jakarta Timur: Khalifa, 2007).
}

Trisno Wardy Putra \& Devita Ayu Fildayanti | Revitalization Of Waqf Management For Social Economic Development Of East Luwu 
Wakaf langsung membutuhkan biaya perawatan yang dananya bersumber dari objek lain diluar benda wakaf. Hal ini dikarenakan wakaf langsung tidak menghasilkan sesuatu dan tidak boleh digunakan untuk tujuan tersebut. Sedangkan pada wakaf produktif, sebagian hasilnya dapat dipergunakan untuk perawatan dan pelestarian objek wakaf, dan selebihnya dapat dibagikan kepada orang-orang yang berhak sesuai dengan tujuan wakaf. ${ }^{19}$

\section{Ekonomi Pembangunan Islam}

Pembangunan ekonomi merupakan pembangunan kemakmuran ekonomi suatu negara untuk kesejahteraan penduduknya (Huda, 2015). Dalam perkembangannya, para ahli ekonomi mendefinisikan ekonomi pembangunan sebagai suatu studi yang ditujukan untuk meningkatkan taraf hidup penduduk di negara-negara yang sedang berkembang dengan memecahkan masalah-masalah utamanya yakni kemiskinan, pengangguran dan pemerataan. ${ }^{20}$ Pembangunan di negara-negara berkembang pada pelaksanaannya telah memunculkan pola, metode, atau model yang berbeda-beda di antara mereka. ${ }^{21}$

Terdapat perbedaan antara sistem ekonomi sekuler dengan sistem ekonomi Islam. Sistem ekonomi sekuler didasarkan pada manusia ekonomi rasional, hukum pasar, dan positivisme. Sementara sistem ekonomi Islam didasarkan pada penyatuan antara yang lahir dan yang batin, antara dunia dan akhirat. Ekonomi Islam adalah sebuah cabang ilmu pengetahuan yang membantu merealisasikan kesejahteraan manusia melalui alokasi dan distribusi sumber daya langka yang sejalan dengan ajaran Islam tanpa memberikan batasan individual atau menciptakan ketidakseimbangan makroekonomi dan ekologi secara berkelanjutan. ${ }^{22}$ Sementara itu, Mannan mendefinisikan ilmu ekonomi Islam sebagai sebuah ilmu pengetahuan sosial yang mempelajari masalah-masalah ekonomi masyarakat yang diilhami oleh nilai-nilai Islam (Islamic economics is a social science which studies the economics problems of a people imbued with the values of Islam). ${ }^{23}$

\footnotetext{
${ }^{19}$ Nasrul Fahmi Zaki Fuadi,Wakaf sebagai Instrumen Ekonomi Pembangunan Islam,Economica: Jurnal Ekonomi Islam,Vol.9 No.1, 2018, h.151-177.

${ }^{20}$ Hasan Aedy, Teori Dan Aplikasi Ekonomi Pembangunan Perspektif Islam, Sebuah Studi Komparasi,(Yogyakarta: Graha IImu, 2011).

${ }^{21}$ Almizan, Pembangunan Ekonomi Dalam Perspektif Ekonomi Islam, Maqdis: Jurnal Kajian Ekonomi IslamVol.1 No.2,2016, h.203-22.

${ }^{22}$ Muhammad Umar Chapra, Masa Depan IImu Ekonomi: Sebuah Tinjauan Islam, (Jakarta: Gema Insani Press, 2001).

${ }^{23}$ Muhammad Abdul Mannan, Ekonomi Islam: Teori Dan Praktek, Yogyakarta: Dana Bhakti Wakaf, 1993).
}

Trisno Wardy Putra \& Devita Ayu Fildayanti | Revitalization Of Waqf Management For Social Economic Development Of East Luwu 
Untuk mengetahui sebuah sistem ekonomi Islam, kita dapat mengetahuinya melalui karakteristik dari ekonomi Islam, di antara karakteristik tersebut adalah sebagai berikut: ${ }^{24}$

1. Harta kepunyaan Allah dan manusia merupakan khalifah atas harta.

2. Ekonomi terikat dengan akidah, syariah (hukum), dan moral.

3. Keseimbangan antara kerohanian dan kebendaan.

4. Ekonomi Islam menciptakan keseimbangan antara kepentingan individu dengan kepentingan umum.

5. Kebebasan individu dijamin dalam Islam.

6. Negara diberi wewenang turut campur dalam perekonomian.

7. Bimbingan konsumsi.

8. Petunjuk investasi.

9. Zakat.

10. Larangan riba.

\section{METODOLOGI PENELITIAN}

Penelitian ini dilaksanakan pada tanggal 20-26 Mei 2021 bertempat di Desa Tawakua, Kecamatan Angkona, Kabupaten Luwu Timur, SulawesiSelatan. Metode yang digunakan dalam penelitian ini adalah deskriptif kualitatif (Descriptive Qualitativ e Approach) dengan pendekatan fenomenologi. Pendekatan ini bermaksud untuk memahami fenomena tentang apa yang dialami oleh subyek penelitian dan dengan metode deskripsi dalam bentuk kata-kata dan bahasa (naratif) pada suatu konteks khusus yang alamiah dan dengan memanfaatkan berbagai metode alamiah. ${ }^{25}$

Jenis data yang digunakan dalam penelitian ini ada dua yakni data primer dan data sekunder. Dimana data primer merupakan data yang dikumpulkan peneliti secara langsung sedangkan data sekunder adalah data yang dikumpulkan peneliti dari berbagai sumber contohnya internet. ${ }^{26}$ Data langsung yaitu dari wawacara sedangkan data tidak langsung didapatkan dari website resmi lembaga-lembaga pemerintahan misalnya BPS (Badan Pusat Statistik). Selain itu data kumpulkan dari berbagai sumber ilmiah seperti skripsi, jurnal, dan esai.

Dalam penelitian ini data dikumpulkan dengan teknik studi wawancara, dokumentasi, studi pustaka, internet dan documenter (documentery study), merupakan suatu teknik pengumpulan data dengan menghimpun dan menganalisis dokumen-dokumen, baik lisan, dokumen

\footnotetext{
${ }^{24}$ Nasrul Fahmi Zaki Fuadi, Wakaf sebagai Instrumen Ekonomi Pembangunan Islam, Economica: Jurnal Ekonomi Islam,Vol.9 No.1, 2018, h.151-177.

${ }^{25}$ Zul Asmi, Memahami Penelitian Kualitatif dalam Akuntansi,Akuntabilitas, Vol.XI No.1, 2018, h.161 26 Ibid
}

Trisno Wardy Putra \& Devita Ayu Fildayanti | Revitalization Of Waqf Management For Social Economic Development Of East Luwu 
tertulis maupun dokumen tidak tertulis seperti gambar dan elektronik yang sesuai dengan kajian penelitian. ${ }^{27}$ Teknik pengambilan data dilakukan kepada 5 informan yang terdiri dari Kepala KUA, Staf KUA sebanyak 2 orang, Sekertaris Desa dan masyarakat yang paham wakaf. Analisis data yang dilaksanakan dalam penelitian ini yakni menerapkan analisis kualitatif yang dilakukan melalui proses tahapan pengumpulan data, pemilihan data, pengkategorian data, penyajiandata, pembandingan data, penyatuan data, dan penarikan data/penafsiran.

\section{HASIL DAN PEMBAHASAN}

Tawakua adalah desa yang berada di Kecamatan Angkona Kabupaten Luwu Timur. Kecamatan Angkona terletak 32 km di jazirah timur ibukota Kabupaten Luwu Timur. Kecamatan ini berbatasan dengan Kecamatan Nuha sebelah utara, Kecamatan Malili dan Nuha sebelah timur. Sementara di sebelah barat berbatasan dengan Kecamatan Kalaena, Kecamatan Tomoni Timur dan Wotu serta bagian selatan berbatasan langsung dengan Teluk Bone. Luas wilayah 147,24 km persegi atau 2,12\% dari luas wilayah Kabupaten Luwu Timur. Kecamatan Angkona terbagi dalam 10 desa, tiga diantaranya merupakan desa pesisir dengan garis pantai sepanjang $16 \mathrm{~km}$ yang banyak ditumbuhi hutan mangrove. Tujuh desa lainnya bukan merupakan desa pesisir dengan topografi wilayahnya datar hingga berbukit dengan ketinggian 3-15 meter di atas permukaan laut.

Pemerintahan pada tahun 2016 di Kecamatan Angkona terdapat 46 dusun dengan 164 Rukun Tetangga (RT). Sebanyak 26 orang pegawai negeri sipil (PNS) terlibat dalam kegiatan pemerintahan di kantor Kecamatan Angkona. Dari jumlah tersebut sebanyak 14 orang merupakan PNS golongan II dan 9 orang lainnya golongan III serta 3 orang golongan I. Berdasarkan tingkat pendidikannya, PNS di lingkup kantor Kecamatan Angkona sebagian besar merupakan lulusan SLTA. Dari 26 pegawai yang ada terdapat II pegawai lulusan SLTA dan 6 pegawai lulusan S1 serta 9 orang lulusan SLTP ke bawah. Menurut jenis kelamin PNS di lingkup kantor lebih di dominasi oleh laki-laki sebanyak 16 orang dan 10 orang perempuan.

Penduduk pada tahun 2016, jumlah penduduk di Kecamatan Angkona sebanyak 25.250 jiwa yang terbagi ke dalam 6.297 rumah tangga dengan rata-rata penduduk dalam satu rumah tangga sebanyak 4 jiwa. Berdasarkan hasil laporan rekapitulasi penduduk pada akhir tahun 2016 kepadatan penduduk di Kecamatan Angkona tergolong tinggi yaitu sekitar $171,48 \mathrm{jiwa} / \mathrm{km}^{2}$. Desa yang terpadat penduduknya adalah Desa Watang

\footnotetext{
${ }^{27}$ Hadi Sutrisno, Metodologi Research 2, (Andi Offset: Yogyakarta, 2004).
}

Trisno Wardy Putra \& Devita Ayu Fildayanti | Revitalization Of Waqf Management For Social Economic Development Of East Luwu 
Panua dengan kepadatan 516 jiwa $/ \mathrm{km}^{2}$, sedangkan yang paling rendah adalah Desa Mantadulu dengan kepadatan sekitar 105 jiwa $/ \mathrm{km}^{2}$.

\section{Peran KUA dalam Pengelolaan Harta Benda Wakaf di Kecamatan Angkona}

KUA Kecamatan Angkona merupakan salah satu KUA di bawah jajaran Kementerian Agama Kabupaten Luwu Timur Propinsi Sulawesi Selatan yang terletak di pusat Kota Kecamatan, tepatnya di Jl. Kelapa Gading No.04 Dusun Waeroya Desa Solo Kecamatan Angkona kode pos 92985. KUA Kecamatan Angkona pada kantor sekarang ini didirikan pada tanggal 11 Februari 2003 di atas lahan seluas $2615 \mathrm{~m}^{2}$ dengan luas bangunan $10 \times 10 \mathrm{~m}^{2}$. Pada saat didirikan wilayah kerjanya meliputi wilayah Kecamatan Angkona, Kecamatan Malili sebelum terjadi pemekaran kecamatan. KUA Kecamatan Angkona sebagai instansi pemerintah dan juga merupakan ujung tombak Kementrian Agama sebagai penanggung jawab pelaksanaan sebagian tugas pemerintahan di bidang agama.

KUA adalah pejabat pembuat akta ikrar wakaf. Secara umum, pengelolaan harta benda wakaf di Kecamatan Angkona sepenuhnya diserahkan kepada nadzir. Setiap wakif akan menentukan siapa nadzir yang akan mengelola atau diberi amanah untuk pengelolaan tanah wakafnya. Penentuan nadzir bebas dari mana saja dan siapa saja karena biasanya nadzir berasal dari masyarakat sekitar. Nadzir akan mengelola tanah wakaf sebagaimana amanah dari wakif yang tercantum dalam akta ikrar wakaf karena sifat wakaf adalah permanen tidak boleh ahli fungsi. Jadi KUA tidak melakukan pengelolaan terhadap harta benda wakaf tetapi semua administrasi atau kelengkapan berkas dan dokumentasi wakaf di urus melalui KUA.

"Kalau KUA disini itu cuman urus kelengkapan berkas dari tanah wakaf saja kayak misalkan akta ikrar wakafnya. Pengelolaannya itu di ambil penuh sama nadzirnya. Penentuan nadzirnya juga dari wakif, terserah wakifnya mau nunjuk siapa untuk jadi nadzir. Pengelolaan wakafnya itu harus sesuai sama apa yang tercantum di dalam akta ikrar wakafnya. Kalau di dalam akta bilang disuruh untuk masjid yah untuk masjid tidak boleh untuk lain"(wawancara dengan Bapak Suwardi, 20/05)

Nadzir terbagi menjadi dua yaitu nadzir pribadi dan nadzir organisasi. Nadzir pribadi ditunjuk untuk mewakili diri pribadi sedangkan nadzir organisasi biasanya mewakili organisasi misalnya tanah di wakafkan ke Nahdatullah, Wahdah, NU.

"Penentuan nadzir itu biasanya ada dua. Satu nadzir pribadi dan satunya lagi nadzir yang mewakili organisasi"(wawancara dengan Bapak Suwardi, 20/05)

Trisno Wardy Putra \& Devita Ayu Fildayanti | Revitalization Of Waqf Management For Social Economic Development Of East Luwu 
Proses pembuatan akta ikrar wakaf harus jelas seperti melengkapi dokumen-dokumen kepemilikan tanah (sertifikat, surat keterangan tanah), status tanah harus jelas dengan menunjukkan nomor persil, tujuan tanah tersebut diwakafkan dan peruntukkannya untuk apa.

"Biasanya dokumen untuk pembuatan akta ikrar wakaf itu harus jelas kepemilikan tanahnya karena jangan sampai tanah gunung yang kosong dan tidak ditau siapa yang punya jadi diakui. Makanya ada nomor persil jadi bisa ditau"(wawancara dengan lbu Suhernawati, 20/05)

Pengelolaan harta benda wakaf di Kecamatan Angkona Kabupaten Luwu timur biasanya dikelola secara langsung di Desa masing-masing. KUA hanya menerima data yang dilaporkan dari Desa. Namun biasanya Desa tidak melaporkan ke KUA melainkan langsung ke Kementerian Agama Kabupaten Luwu Timur. Sehingga data mengenai harta benda wakaf di KUA sangat terbatas. Hal tersebut terjadi karena tidak adanya ketentuan yang mengikat sehingga proses administrasi tidak menetap melainkan tergantung dari Desa masing-masing.

"Biasanya desa itu langsung setor berkasnya ke kemenag kabupaten. Ada beberapa yang kesini tapi biasanya cuman minta blanko sama tanda tangan saja sebagai persetujuan akta ikrar wakafnya tapi biasanya juga tidak. Makanya data disini itu tidak lengkap" (wawancara dengan Ibu Evy Nurjannah, 20/05)

\section{Pengelolaan Harta Benda Wakaf di Desa Tawakua Kecamatan Angkona Luwu Timur}

Desa Tawakua adalah salah satu desa yang terletak di Kecamatan Angkona Kabupaten Luwu Timur. Pengelolaan harta benda wakaf di Desa Tawakua sepenuhnya dikelola oleh pemerintah desa. Sangat jarang sekali masyarakat melakukan wakaf karena biasanya hanya orang kaya yang memawakafkan hartanya. Benda wakaf yang paling dominan di wakafkan adalah tanah.

"Disini itu jarang orang berwakaf kalaupun ada paling cuman beberapa dan itu memang orang kaya. Biasanya yang diwakafkan itu tanah"(wawancara dengan Bapak Sadiman, 26/05)

Wakaf yang masyarakat berikan biasanya diperuntukkan untuk masjid dan untuk keperluan desa misalnya untuk pembangunan pos atau siskampling di setiap dusun atau keperluan desa lainnya.

"kalau sekarang itu masyarakat biasa wakaf untuk masjid atau untuk desa. Desa itu biasanya untuk pos di setiap dusun" (wawancara dengan Bapak Adi, 26/05)

Trisno Wardy Putra \& Devita Ayu Fildayanti | Revitalization Of Waqf Management For Social Economic Development Of East Luwu 
Setiap orang yang akan mewakafkan hartanya akan melapor ke pihak desa. Desa yang akan membantu proses perwakafan tanah tersebut. Tetapi biasanya nadzir adalah wakif, artinya wakif yang akan mengelola sendiri harta wakafnya sesuai dengan ketentuan yang tercantum di dalam akta ikrar wakaf. Jadi desa hanya sebagai perantara dalam proses pengurusan akta ikrar wakaf.

Nadzir itu tidak ada kalau disini karena yang jadi nadzir yahh wakifnya sendiri. Desa cuman bantu untuk urus akta ikrar wakafnya saja" (wawancara dengan Bapak Adi, 26/05)

Pengetahuan masyarakat sangat minim terkait wakaf, bahkan sumber daya manusia yang paham akan wakaf sangat minim. Masyarakat hanya mengetahui wakaf seperti halnya sedekah dan infaq dan menganggap hal tersebut tidak terlalu penting untuk dilaksanakan. Latar belakang pendidikan, tidak adanya perhatian dari pemerintah setempat untuk memberikan edukasi kepada masyarakat sehingga wakaf di desa tidak bisa berkembang dengan baik. Hal inilah yang menjadi salah satu penyebab wakaf di Desa sangat kecil.

"masyarakat disini itu mana tau wakaf, paling yang ditau cuman wakaf tanah.belum pernah juga ada sosialisasi terkait wakaf" (wawancara dengan Bapak Sadiman, 26/05)

\section{Revitalisasi Pengelolaan Harta Benda Wakaf}

Peran wakaf sangat penting dalam pembangunan sosial ekonomi umat. Namun kurangnya kesadaran masyarakat ataupun pemerintah sehingga manajemen pengelolaan wakaf menjadi tidak optimal. Apalagi ditambah dengan minimnya pengetahuan masyarakat terkait wakaf khususnya di Desa Tawakua Kecamatan Angkona. Masyarakat tidak mengetahui bahwa wakaf itu penting bagi kesejahteraan ekonomi mereka. Seperti halnya zakat yang mereka ketahui hanyalah zakat fitrah saja yang wajib ditunaikan pada saat bulan suci ramadhan. Padahal ada juga zakat mal yang kedudukannya sama-sama wajib dengan zakat fitrah. Begitu pula dengan wakaf, yang masyarakat ketahui bahwa wakaf itu hanya ada wakaf tanah karena mereka menganggap bahwa yang bersifat tunai itu hanya sedekah dan infaq saja.

Melihat hal tersebut perlu dilakukan revitalitalisasi pengelolaan harta wakaf dengan tujuan selain memberikan pemahaman dan edukasi kepada masyarakat terkait wakaf tetapi dapat juga memperbaiki sistem pengelolaan harta benda wakaf yang ada di Desa Tawakua Kecamatan Angkona Kabupaten Luwu Timur agar menjadi produktif. Revitalisasi tersebut dapat dilakukan dengan cara membuat website resmi wakaf desa yang bekerja sama dengan KUA Kecamatan Angkona dan Kementerian

Trisno Wardy Putra \& Devita Ayu Fildayanti | Revitalization Of Waqf Management For Social Economic Development Of East Luwu 
Agama Kabupaten Luwu Timur. Website ini dapat dijadikan pedoman atau acuan bagi masyarakat yang sangat minim pengetahuannya mengenai wakaf. Di dalam website ini menyediakan berbagai fitur-fitur yang dapat melayani dan memberikan informasi kepada masyarakat terkait wakaf sehingga masyarakat juga dapat mengontrol dan update terkait perkembangan informasi wakaf. Website ini juga dijadikan sebagai situs resmi pengelolaan wakaf sehingga pengelolaan wakaf lebih terstruktur.

\section{E. KESIMPULAN}

Berdasarkan hasil penelitian dapat disimpulkan bahwa perlu adanya revitalisasi untuk pengelolaan wakaf di Desa Tawakua Kecamatan Angkona Kabupaten Luwu Timur agar fungsi wakaf sebagai instrumen pembangunan ekonomi dapat tercapai dengan baik. Revitalisasi tersebut dapat dilakukan dengan cara membuat website resmi wakaf desa yang bekerja sama dengan KUA Kecamatan Angkona dan Kementerian Agama Kabupaten Luwu Timur. Website ini dapat dijadikan pedoman atau acuan bagi masyarakat yang sangat minim pengetahuannya mengenai wakaf.

\section{Referensi}

Aedy, H. (2011). Teori Dan Aplikasi Ekonomi Pembangunan Perspektif Islam, Sebuah Studi Komparasi. Yogyakarta: Graha Ilmu.

Almizan. (2016). Pembangunan Ekonomi Dalam Perspektif Ekonomi Islam. Maqdis: Jurnal Kajian Ekonomi Islam. 1(2): 203-22.

Asmi, Z. (2018). Memahami Penelitian Kualitatif dalam Akuntansi. Akuntabilitas. XI(1), 161.

Badan Pusat Statistik. Jumlah Penduduk dan Penduduk Muslim di Kabupaten Luwu Timur. luwutimurkab.bps.go.id di Akses Pada Tanggal 30 Mei 2021 Pukul 09.55 WITA.

Badan Wakaf Indonesia. Menelisik Manfaat Potensi Wakaf Uang Untuk Bantu Kaum Duafa. www.bwi.go.id di Akses Pada Tanggal 30 Mei 2021 Pukul 12.30 WITA.

Chapra, M.U. (2001). Masa Depan IImu Ekonomi: Sebuah Tinjauan Islam. Jakarta: Gema Insani Press.

Fauza, N. (2015). Rekonstruksi Pengelolaan Wakaf: Belajar Pengelolaan Wakaf dari Bangladesh dan Malaysia. Universum. 9(2), 162-170.

Fuadi, N.F.Z. (2018). Wakaf sebagai Instrumen Ekonomi Pembangunan Islam. Economica: Jurnal Ekonomi Islam. 9(1), 151-177.

Hidayaty, FN. (2011). Pengaruh Sosialisasi Perhitungan Praktis Zakat Mal Oleh Pengurus LAZ Terhadap Kesadaran Para Muzakki Untuk

Trisno Wardy Putra \& Devita Ayu Fildayanti | Revitalization Of Waqf Management For Social Economic Development Of East Luwu 
Berzakat Pada Zakat Center Thoriqhotul Jannah Cirebon. Institut Agama Islam Negeri Syekh Nurjati Cirebon.

Huda, Nurul. (2015). Ekonomi Pembangunan Islam. Jakarta: Kencana.

Isfandiar, A.A. (2008). Tinjauan Fiqh Muamalat dan Hukum Nasional tentang Wakaf di Indonesia. La_Riba: Jurnal Ekonomi Islam. II(1), 5356 .

Jubaedah. (2017). Dasar Hukum Wakaf. TAZKIYA: Jurnal Keislaman, Kemasyarakatan dan Kebudayaan. 18(2), 256-265.

Kholisdinuka, A. Jumlah Penduduk Muslim di Indonesia. https://news.detik.com di Akses Pada Tanggal 30 Mei 2021 Pukul 09.14 WITA.

Mannan, M.A. (1993). Ekonomi Islam: Teori Dan Praktek. Yogyakarta: Dana Bhakti Wakaf.

Medias, F. (2010). Wakaf Produktif Dalam Perspektif Ekonomi Islam. La_Riba. 4(1), 71-86.

Munir, A.S. (2015). Optimalisasi Pemberdayaan Wakaf Secara Produktif. Jurnal Ummul Qura. VI(2), 94-105.

Munir, Z.A. (2013). Revitalisasi Manajemen Wakaf sebagai Penggerak Ekonomi Masyarakat. Journal de Jure. 5(2), 162-171.

Nissa, C. (2017). Sejarah, Dasar Hukum dan Macam-macam Wakaf. TAZKIYA: Jurnal Keislaman, Kemasyarakatan dan Kebudayaan. 18(2), 214-217.

Pemerintah Kabupaten Luwu Timur. Profil Kecamatan Angkona. portal.luwutimurkab.go.id di Akses pada Tanggal 30 Mei 2021 Pukul 17.35 WITA.

Qahaf, Mundzir. (2007). Manajemen Wakaf Produktif. Jakarta Timur: Khalifa.

Suganda, A.D. (2004). Konsep Wakaf Tunai. Jurnal Ekonomi Islam. 5(2), 59.

Sutrisno, H. (2004). Metodologi Research 2. Andi Offset: Yogyakarta.

Syafiq, M. (2018). Peningkatan Kesadaran Masyarakat dalam Menunaikan Zakat, Infaq, Sedekah dan Wakaf (ZISWAF). Jurnal Zakat dan Wakaf. 5(2), 363-385.

Thayyeb, Y.Y. (2012). Pengelolaan Wakaf Produktif Di Mesir. Al-Awqaf: Jurnal Wakaf Dan Ekonomi Islam. 7(2), 1-1.

Trisno Wardy Putra \& Devita Ayu Fildayanti | Revitalization Of Waqf Management For Social Economic Development Of East Luwu 